\title{
A FORMAÇÃO DE TÉCNICOS EM GESTÃO NOS SERVIÇOS DE SAÚDE: REPERCUSSÃO NO PROCESSO DE TRABALHO E ARTICULAÇÃO ENTRE TEORIA E PRÁTICA
}

\author{
Maria Jalila Vieira de Figueirêdo Leite \\ Professora da EEN/UFRN. Mestre em Odontologia Social. E-mail: jalilaleite@ ufrnet.br \\ Bárbara Cássia de S. Farias Santos \\ Cirurgiã-dentista. Especialista em Saúde Coletiva. CEFOPE/RN. \\ E-mail: bfarias0507@ hotmail.com \\ Rita de Cássia T. de Oliveira \\ Nutricionista. Especialista em Nutrição. CEFOPE/RN. E-mail: rcassia.nutri@yahoo.com.br \\ Francisca Kátia Batista Gomes \\ Técnica em Nutrição e Dietética. Hospital Dr.José Pedro Bezerra/RN. \\ E-mail:franciscakatia@gmail.com \\ Eliziete de Oliveira Silva \\ Técnica em Nutrição e Dietética. Hospital Dr.José Pedro Bezerra/RN. \\ E-mail: elizietesilva@hotmail.com \\ Joseneide dos Santos \\ Técnica em Nutrição e Dietética. Hospital Dr.José Pedro Bezerra/RN. \\ E-mail: nutrijose@hotmail.com \\ Dante Henrique Moura \\ Professor do IFRN. Doutor em Educação. E-mail: dante@ @efetrn.br
}

\section{RESUMO}

O estudo objetivou identificar e analisar a opinião dos egressos e docentes do Curso de Técnico em Gestão nos Serviços de Saúde do Centro de Formação de Pessoal para os Serviços de Saúde (CEFOPE/RN), bem como de suas chefias imediatas nos serviços de saúde, sobre a implementação dos conhecimentos teórico-práticos adquiridos, no processo de trabalho; sobre a articulação teoria e prática no processo pedagógico adotado; e quanto à relação existente entre o CEFOPE/RN e os serviços de saúde. Utilizou uma metodologia quanti-qualitativa, com a aplicação de questionários e grupos focais, junto a 27 egressos, nove docentes e nove chefes imediatos. Os resultados evidenciaram que: os conhecimentos apreendidos no curso possibilitam melhor desempenho do egresso; há uma articulação entre a teoria e a prática, no entanto persistem alguns conflitos e incompreensões; algumas dificuldades foram apontadas quanto à relação do CEFOPE/RN com os serviços de saúde.

PALAVRAS-CHAVES: Gestão em saúde, educação profissional, trabalho em saúde.

\section{TRAINING OF TECHNICIANS IN HEALTH CARE MANAGEMENT: REPERCUSSION IN THE LABOR PROCESS AND ARTICULATION BETWEEN THEORY AND PRACTICE}

\begin{abstract}
The study aimed to identify and analyze the views of former students and teachers of Technical Course in Health Services, in Training Centre of Personal Health Services, as well
\end{abstract}


as their immediate supervisors about the implementation of theory and practical knowledge acquired in the work process, about the theory and practice adopted in the educational process and about the relationship between CEFOPE/RN and health services. We used quantitative and qualitative methodologies - questionnaires and focus groups with 27 former students, nine teachers and nine immediate supervisors. The results showed that the knowledge learned in the course can improve the performance of the former students, there is a link between theory and practice, however some conflicts, incomprehensions and some difficulties were identified regarding the relationship of CEFOPE/RN with health services.

KEY- WORDS: health management, professional education, health work 


\section{A FORMAÇÃO DE TÉCNICOS EM GESTÃO NOS SERVIÇOS DE SAÚDE: REPERCUSSÃO NO PROCESSO DE TRABALHO E ARTICULAÇÃO ENTRE TEORIA E PRÁTICA}

\section{INTRODUÇÃO}

Esta Pesquisa integrou o Programa de Incentivo à Pesquisa nas Escolas Técnicas do SUS, aprovado em uma chamada pública para seleção de propostas, realizada pelo Ministério da Saúde, através do Departamento de Gestão da Educação na Saúde/Secretaria de Gestão do Trabalho e da Educação na Saúde, no início de 2006. Sua concepção está referenciada na produção teórica de autores que se dedicam ao tema Educação Profissional, especialmente na sua visão politécnica.

A formação de trabalhadores de nível médio e elementar na área da saúde no Brasil emerge nos anos 70 como tentativa de responder às precárias condições de saúde da população e ineficiência dos serviços de saúde. Neste aspecto, a formação de recursos humanos passa a ser compreendida como uma estratégia fundamental para reversão desta situação. Em continuidade a outras iniciativas de preparação de pessoal para atuar nos serviços de saúde, a partir da década de 80, o Ministério da Saúde estimula em todo o país, a implementação de projetos destinados à formação de pessoal de nível médio e elementar pelas próprias instituições de saúde, mais precisamente pelas secretarias de saúde de cada unidade federada.

No que se refere à formação de trabalhadores de nível médio para o Sistema Único de Saúde (SUS) pressupõe-se uma preparação de profissionais com domínio técnico, científico e consciência crítica, que permita a esses atores se reconhecerem como sujeitos de transformação. Um dos maiores desafios a ser enfrentado é transitar nas dimensões educação e saúde, incorporando elementos que possibilitem traduzir os ideais de uma educação transformadora, capaz de transcender a preparação mecanicista para atuar no processo de trabalho em saúde. Trabalhar nesta perspectiva exige uma ruptura com a lógica da transmissão do saber fragmentado e a assunção de propostas pedagógicas que compreendam a escola como lugar de construção do conhecimento, onde trabalho, ciência e cultura se tornem categorias fundamentais para a elaboração e a operacionalização dos currículos.

No ano de 2000, o Ministério da Saúde cria, por meio da Portaria ${ }^{\circ} 1.298$, de 28/11/2000, a Rede de Escolas Técnicas do SUS (RET-SUS), com o objetivo de facilitar a articulação técnica e política entre as Escolas Técnicas do SUS e fortalecer a educação profissional em Saúde (SÓRIO, 2002). Composta por 37 instituições públicas e uma Comissão Geral de Coordenação, a RET-SUS tem como objetivo a formação dos trabalhadores de nível médio do Sistema Único de Saúde.

O Centro de Formação de Pessoal para os Serviços de Saúde Dr. Manoel da Costa Souza do Estado do Rio Grande do Norte (CEFOPE/RN) integra a Rede de Escolas Técnicas do SUS (RET-SUS) e reconhece que o processo formativo desenvolvido é permeado por tensões e contradições, relacionadas principalmente à integração ensino e serviço. Tais dificuldades impõem à escola a necessidade de avaliar se sua prática educativa está contribuindo para o exercício da reflexão que possibilite o reconhecimento da realidade e a necessidade de sua transformação, provocando uma melhoria da qualidade dos serviços de saúde, uma vez que o seu projeto pedagógico explicita a intenção de tomar esses mesmos serviços como um dos eixos de uma formação integral. 
O Projeto Político Pedagógico (PPP) adotado pelo CEFOPE/RN toma como base referencial o compromisso de contribuir para a construção de uma sociedade democrática, participativa, justa, solidária, humana e fraterna. O trabalho pedagógico tem como eixo a cidadania, compreendendo a educação profissional como um processo permanente de aquisição/(re)estruturação de conhecimentos, habilidades, valores e comportamentos inerentes ao desenvolvimento de competências para o desempenho de uma determinada profissão (RIO GRANDE DO NORTE, 2004).

O PPP se compromete ainda com a superação da tendência do "tecnicismo pedagógico" em direção a uma formação com acesso a conhecimentos científicos e tecnológicos, bem como com o desenvolvimento de tecnologias apropriadas à realidade local e regional, respeitando os conhecimentos e experiências dos participantes, orientando-se por uma pedagogia fundamentada numa concepção crítica das relações existentes entre educação, sociedade e trabalho (RIO GRANDE DO NORTE, 2004).

O modelo pedagógico orientado no PPP baseia-se nos princípios da flexibilidade; interdisciplinaridade e contextualização; princípios e diretrizes do SUS; maior articulação teoria-prática; permanente interlocução com o mundo do trabalho; atualização dos cursos e currículos em consonância com as necessidades dos trabalhadores e do mundo do trabalho; e do paradigma da produção social da saúde (RIO GRANDE DO NORTE, 2004).

Assim, o PPP do CEFOPE/RN caminha em direção ao ideário da politecnia, que resgata o princípio da formação humana em sua totalidade, defendendo um ensino que integre o trabalho, a ciência e a cultura, em prol do desenvolvimento da potencialidade humana dos seus alunos.

Segundo Saviani (2003), a noção de politecnia deriva, basicamente, da problemática do trabalho, que define a existência humana, encaminhando-se na direção da superação da dicotomia entre trabalho manual e trabalho intelectual, entre instrução profissional e instrução geral, superando concepções antigas que compreendiam o ensino profissional como destinado àqueles que deveriam executar e o ensino científico-intelectual àqueles que deveriam conceber e controlar o processo. Neste caso, o processo de trabalho se desenvolve em uma unidade indissolúvel, nos aspectos manuais e intelectuais.

Assim sendo, a compreensão de politecnia avança em relação ao conceito ampliado, que diz respeito ao domínio dos fundamentos científicos das diferentes técnicas que caracterizam o processo de trabalho produtivo moderno e não na definição literal de que politécnica significaria apenas a multiplicidade de técnicas. O trabalhador, a partir do domínio desses princípios estaria em condições de desenvolver as diferentes modalidades de trabalho, com a compreensão do seu trabalho, da sua essência (SAVIANI, 2003).

Diante destas considerações foram elaboradas as seguintes questões para o estudo: 1) Os egressos do Curso Técnico em Gestão nos Serviços de Saúde implementam os conhecimentos teórico-práticos adquiridos segundo as necessidades do processo de trabalho? 2) O processo pedagógico adotado e os respectivos conteúdos do Curso Técnico em Gestão nos Serviços de Saúde articula teoria e prática? 3) O CEFOPE/RN estabelece relações com as Unidades Hospitalares onde seus egressos atuam? Como ela se dá?

Com base nestas indagações foram delineados os seguintes objetivos: identificar e analisar a opinião dos egressos e docentes do Curso de Técnico em Gestão nos Serviços de Saúde, bem como das chefias imediatas, sobre a implementação dos conhecimentos teórico-práticos 
adquiridos no curso no processo de trabalho; caracterizar, segundo a opinião dos participantes, a articulação teoria e prática no processo pedagógico adotado no CEFOPE/RN; identificar a relação existente entre CEFOPE/RN e os serviços de saúde.

\section{METODOLOGIA}

Trata-se de um estudo descritivo cuja temática foi abordada utilizando recursos analíticos proporcionados pela pesquisa qualitativa, integrada ao instrumental da quantificação. A associação dessas abordagens, além de não se caracterizarem como contraditórias, apenas serem de natureza diferente, na verdade são instrumentos para melhor aproximação à realidade observada. Nenhuma das duas é suficiente para a compreensão completa da realidade e nenhuma é mais científica do que a outra. Assim, o estudo quantitativo pode gerar questões para serem aprofundadas qualitativamente, e vice-versa (MINAYO, SANCHES, 1993).

Nessa perspectiva, Minayo (2005) defende a triangulação, não como um método em si, mas como uma estratégia de pesquisa que se apóia em métodos científicos testados e consagrados, servindo e adequando-se a determinadas realidades, com fundamentos interdisciplinares. As abordagens disciplinares quantitativas $\mathrm{e}$ qualitativas, em $\mathrm{si}$ e as possibilidades interdisciplinares destas abordagens se combinarem, produzem a triangulação. Na estratégia da triangulação há um cuidado analítico, tanto estatístico, como compreensivo, antecedendo ao balizamento metodológico e interdisciplinar (MINAYO, 2005).

A pesquisa foi desenvolvida no município de Natal, capital do Estado do Rio Grande do Norte, mais especificamente no CEFOPE/RN. O curso de Técnico em Gestão nos Serviços de Saúde, autorizado pela Secretaria de Estado da Educação, Cultura e Desportos em abril de 2005 tem como proposta a formação de um profissional capacitado para atuar de forma próativa nas atividades administrativas dos serviços de saúde, interagindo sistematicamente com os usuários, apontando para o seu potencial cognitivo, focado na humanização e eficácia dos serviços. Este técnico está habilitado para exercer suas funções em Unidades Básicas de Saúde, Centros de Referência e Hospitais, com competências em diferentes áreas, entre elas: planejamento estratégico, gestão de pessoas, de material e patrimônio, orçamentária, financeira e contábil, gestão em serviços logísticos e gerais.

O Curso, com 1.200 horas, estrutura-se em módulos de forma a garantir flexibilidade aos alunos no momento de construírem seus intinerários de formação de acordo com suas necessidades e interesses.

O Plano de Curso descreve que o trabalho em sala de aula será estruturado em torno de áreas temáticas, visando a integração dos componentes curriculares e a articulação do saber escolar com os conhecimentos prévios do aluno, de forma que o processo de construção do conhecimento seja um processo partilhado por professores e alunos.

Foram selecionados para participar da investigação 27 alunos da primeira turma do Curso Técnico em Gestão nos Serviços de Saúde oferecido pelo CEFOPE/RN, ocorrido no período de julho de 2006 a dezembro de 2007.

No momento do curso, estes alunos tinham ensino médio completo e já exerciam gerências intermediárias em diferentes setores administrativos de Unidades Hospitalares, no entanto não dispunham de formação específica para tal desempenho. Os egressos incluídos no estudo 
atuavam em 5 Unidades Hospitalares do município de Natal, sob gestão da Secretaria de Estado da Saúde Pública do RN e distribuíam-se na seguinte conformidade: Hospital Monsenhor Walfredo Gurgel (4 alunos), Hospital Dr. João Machado (4 alunos), Hospital Infantil Maria Alice Fernandes (1 aluna), Hospital Giselda Trigueiro (6 alunos) e Hospital Dr. José Pedro Bezerra (12 alunos). Participaram ainda da pesquisa nove docentes do Curso em questão e nove chefias imediatas dos egressos, totalizando assim 45 participantes.

Foram utilizadas três técnicas para coletas de dados: a análise documental, a aplicação de questionários e a realização de grupos focais junto aos alunos, docentes e chefias imediatas. A análise documental buscou identificar, conhecer e analisar documentos relacionados ao desenvolvimento do curso, quais sejam: o Projeto Político-Pedagógico do CEFOPE/RN e o Plano do Curso.

Nos questionários, buscou-se identificar as opiniões dos sujeitos em relação às questões apresentadas, segundo o grau de concordância com a afirmação exposta na questão, a qual variava de "0", significando nenhuma concordância, "1", pouca concordância, "2" média concordância, "3" alta concordância e "4" muito alta concordância. Obteve-se respostas a 33 questionários, sendo 22 alunos, 6 docentes e 5 chefes.

Foram construídos questionários específicos para os alunos, docentes e chefias imediatas, porém que abordavam os mesmos temas inerentes às questões do estudo. Esta decisão permitiu a análise por triangulação, com confronto entre as opiniões dos diferentes sujeitos da pesquisa.

A partir de uma análise prévia dos resultados obtidos nos questionários, onde foram avaliados os pontos que mereceriam um aprofundamento das informações, foram estruturados três grupos focais, que obedeceram a seguinte composição: dez alunos representantes dos hospitais; nove docentes e cinco chefes. Participaram efetivamente das reuniões, nove alunos, sete docentes e quatro chefes. Elaborou-se, coletivamente, para condução dos grupos, um roteiro cuja finalidade era promover entre os sujeitos da pesquisa uma reflexão acerca do trabalho como eixo da formação de técnicos de nível médio e o desafio de articular teoria e prática. As perguntas formuladas nos diferentes grupos contemplavam as questões do estudo. Os participantes eram instigados a emitirem suas opiniões e debatê-las com os colegas.

A escolha da técnica de grupo focal justificou-se em função da necessidade de compreender como os sujeitos constroem a realidade e as práticas cotidianas a partir da sua interação com o grupo, considerando as experiências, crenças, atitudes e valores individuais e coletivos. A técnica permite que o pesquisador explore em profundidade um tema ou tópico e obtenha uma significativa quantidade de dados em um curto espaço de tempo. Ademais, sentimentos e reações emergentes face aos temas discutidos podem oferecer pistas de como o grupo se comporta no trabalho coletivo (GATTI, 2005). Além dos aspectos teórico-metodológicos, a utilização dessa técnica fez-se necessária em razão dos objetivos deste estudo, que pretendeu envolver uma significativa quantidade de atores dos serviços de saúde e da escola.

A formação dos grupos observou as orientações de Gatti (2005). A composição se baseou em características homogêneas dos pesquisados e o número de participantes se situou preferencialmente entre seis a doze pessoas, visando não limitar a participação, a troca de idéias e o aprofundamento dos temas.

Os egressos participantes do grupo focal foram escolhidos intencionalmente, procedimento apontado por Minayo (1996) e Gatti (2005) como bastante adequado nos casos de estudos 
menores e em profundidade, onde o pesquisador faz a seleção dos sujeitos com base em características conhecidas e na sua ligação com o problema a ser investigado. A conformação do grupo foi realizada com os critérios de representatividade dos hospitais em relação ao total de egressos e representatividade dos setores dos hospitais.

A análise dos dados dos grupos focais foi realizada nas seguintes etapas: transcrição das entrevistas; identificação das falas de acordo com as categorias da pesquisa e seu grupo focal; análise das falas, com construção das paráfrases; alinhamento das paráfrases convergentes ou divergentes, conforme temas; e elaboração de síntese analítica, por temas.

Ao fim, os dados quantitativos e qualitativos foram agrupados em categorias que, segundo Minayo (1994) abrangem elementos relacionados entre si em função de aspectos ou características comuns. O agrupamento de idéias ou temas em torno de conceitos possibilitou a análise das respostas dos entrevistados e das situações observadas nos serviços e na escola. As categorias foram estabelecidas a posteriori, de acordo com os dados encontrados no trabalho de campo. São elas: a articulação entre a teoria e a prática e a repercussão da formação profissional nas mudanças no processo de trabalho; o currículo e seus componentes; a relação estabelecida entre a Escola e os Serviços de Saúde.

A coleta de dados foi realizada no período de junho a dezembro de 2008 e obedeceu ao Protocolo de Pesquisa aprovado pelo Comitê de Ética em Pesquisa da Universidade Federal do Rio Grande do Norte, através do Parecer Consubstanciado $\mathrm{n}^{\circ}$ 21/2006. Assim, os participantes receberam informações relacionadas aos procedimentos de pesquisa e assinaram os Termos de Consentimentos Livre e Esclarecido autorizando a análise e publicação dos resultados.

\section{RESULTADOS E DISCUSSÃO}

\section{A ARTICULAÇÃO ENTRE TEORIA E PRÁTICA E A REPERCUSSÃO DA FORMAÇÃO PROFISSIONAL NAS MUDANÇAS NO PROCESSO DE TRABALHO}

A análise dos dados dos questionários permitiu identificar que os docentes foram os que mais concordaram quanto à relação do conhecimento ofertado no curso com as necessidades do trabalho $(83 \%)$, os egressos apresentaram graus de concordância um pouco menores enquanto a maioria dos chefes informou que faltavam elementos para avaliar a questão (Tabela 1).

Tabela 1- Distribuição percentual das opiniões dos participantes quanto à relação do conhecimento com as necessidades do trabalho, no curso de técnico em gestão. Natal/RN, 2008

\begin{tabular}{cccc}
\hline Concordância & Egressos (\%) & Docentes (\%) & Chefias (\%) \\
\hline Nenhuma & - & - & - \\
Pouca & 5 & - & - \\
Média & 10 & - & - \\
Alta & 55 & 17 & 40 \\
Muito alta & 25 & 83 & - \\
Faltam Elementos & 5 & - & 60 \\
\hline Total & $\mathbf{1 0 0}$ & $\mathbf{1 0 0}$ & $\mathbf{1 0 0}$ \\
\hline
\end{tabular}


Em relação ao fato dos conhecimentos adquiridos possibilitarem um melhor desempenho profissional, a maioria, tanto de docentes como de egressos apresentaram concordância muito alta, e as chefias, alta concordância (Tabela 2).

Tabela 2 - Distribuição percentual das opiniões dos participantes quanto aos conhecimentos adquiridos possibilitarem um melhor desempenho profissional no curso de técnico em gestão. Natal/RN, 2008

\begin{tabular}{cccc}
\hline Concordância & Egressos (\%) & Docentes (\%) & Chefias (\%) \\
\hline Nenhuma & - & - & - \\
Pouca & - & - & - \\
Média & 5 & - & 40 \\
Alta & 30 & - & 60 \\
Muito alta & 60 & 67 & - \\
Faltam & 5 & 33 & - \\
Elementos & & & $\mathbf{1 0 0}$ \\
\hline Total & $\mathbf{1 0 0}$ & $\mathbf{1 0 0}$ & \\
\hline
\end{tabular}

No que diz respeito aos conhecimentos adquiridos contribuírem para mudanças nas concepções de atenção à saúde vigentes, no grupo dos egressos ocorreu alto nível de concordância, nos docentes, as opiniões distribuíram-se de forma semelhante entre alta e muito alta concordância, e no grupo das chefias houve alta concordância com a afirmação (Tabela 3).

Tabela 3 - Distribuição percentual das opiniões dos participantes quanto aos conhecimentos adquiridos contribuírem para mudar suas concepções de atenção à saúde no curso de técnico em gestão. Natal/RN, 2008

\begin{tabular}{cccc}
\hline Concordância & Egressos $(\boldsymbol{\%})$ & Docentes $\mathbf{( \% )}$ & Chefias (\%) \\
\hline Nenhuma & - & - & - \\
Pouca & - & - & - \\
Média & 5 & 17 & 40 \\
Alta & 33 & 33 & 60 \\
Muito alta & 57 & 33 & - \\
Faltam & 5 & 17 & - \\
Elementos & & & $\mathbf{1 0 0}$ \\
\hline Total & $\mathbf{1 0 0}$ & $\mathbf{1 0 0}$ &
\end{tabular}

Nos grupos focais, entre os docentes foi possível identificar elementos que qualificam a concordância com os achados que emergiram da análise dos questionários, com maior ênfase no fato de que, segundo eles, o conhecimento teórico permite aos egressos identificarem o sentido do seu trabalho, sendo uma oportunidade para melhorar a atuação profissional por meio da introdução de mudanças no processo de trabalho.

Destacaram ainda o fato de que as práticas administrativas não se reduzem à repetição de técnicas aprendidas no dia-a-dia com os colegas com maior tempo de trabalho - embora essa seja uma prática corrente no cotidiano dos hospitais vinculados à Secretaria de Saúde/RN. Segundo os egressos e os próprios chefes, exigem conhecimentos teóricos, tanto quanto em outras áreas. Esta última afirmação pode explicar a tardia valorização da formação dos profissionais que lidam na área de gestão.

No grupo focal, os chefes imediatos avaliaram que muitas práticas administrativas realizadas nas unidades hospitalares estavam defasadas em relação ao atual conhecimento, apontando 
para a necessidade premente de processos de formação que contribuam para mudanças no atual modelo de gestão no sentido de proporcionar maior protagonismo dos trabalhadores da saúde. Apontam, de forma praticamente unânime, que se essa formação for oportunizada haverá boas perspectivas de mudanças nos processos de trabalho. Acrescentam ainda que tal formação, necessariamente associada à prática é um desafio, devido às dificuldades próprias dos serviços.

Já a maioria dos egressos, no grupo focal, se dedicou a reforçar a importância das práticas estarem embasadas em conhecimentos teóricos, mesmo considerando a dificuldade da articulação teoria e prática, devido às realidades das unidades serem muito diferentes. Reforçaram ainda a importância de terem levado para a sala de aula suas experiências de trabalho, qualificando o processo de aprendizagem e favorecendo uma formação crítica e reflexiva.

Quando os sujeitos da pesquisa foram estimulados a opinarem sobre a necessidade do planejamento das aulas contemplarem a articulação entre a teoria e a prática, a maioria dos egressos e chefias apresentou concordância alta e os docentes, concordância muito alta (Tabela 4).

\section{Tabela 4 - Distribuição percentual das opiniões dos participantes quanto à necessidade do planejamento das aulas contemplarem a articulação entre a teoria e a prática, no} curso de técnico em gestão. Natal/RN, 2008

\begin{tabular}{cccc}
\hline Concordância & Egressos (\%) & Docentes (\%) & Chefias (\%) \\
\hline Nenhuma & - & - & - \\
Pouca & 5 & - & - \\
Média & 15 & - & - \\
Alta & 55 & - & 60 \\
Muito alta & 20 & 100 & - \\
Faltam & 5 & - & 40 \\
Elementos & & & \\
\hline Total & $\mathbf{1 0 0}$ & $\mathbf{1 0 0}$ & $\mathbf{1 0 0}$
\end{tabular}

Nos grupos focais, os docentes reforçaram esta questão reafirmando o espaço de sala de aula como um espaço de troca, onde eles se apropriavam das realidades das unidades hospitalares e os egressos dos conhecimentos técnico-científicos que fundamentam o funcionamento desses hospitais. Dessa forma, dizem os docentes, é possível apropriar-se de especificidades do espaço em que ocorre a aplicação dos conhecimentos adquiridos pelos egressos no seu trabalho. Os docentes avaliam ainda que se o estudante não encontra relação do trabalho com o que ele aprende em sala de aula não há mudança no processo de trabalho.

Embora os egressos tenham apresentado alta concordância com a afirmação da Tabela 4, no grupo focal evidenciaram dificuldades para utilizar na prática os conhecimentos adquiridos em sala de aula. Em 18 depoimentos houve relato de dificuldades nesse campo e apenas três avaliando suas possibilidades e benefícios. Os chefes acompanharam essa constatação com oito falas indicando as dificuldades e nenhum aspecto positivo. Até entre os docentes houve maior registro de falas indicando dificuldades (três) e apenas uma ressaltou aspectos positivos. Estes resultados apontam as contradições entre as respostas obtidas nos questionários e os depoimentos nos grupos focais.

Aprofundando um pouco mais a análise acerca dos motivos das facilidades ou dificuldades de levar à prática os conhecimentos adquiridos no curso, nos grupos focais foi possível 
identificar que, do ponto de vista dos egressos, as facilidades ocorreram em determinados espaços de trabalho, onde o apoio da gestão foi decisivo. Por outro lado, os egressos enfatizaram que as dificuldades não podem ser atribuídas somente à falta de apoio dos gestores, mas à estrutura do serviço e especialmente à falta de apoio dos próprios colegas de equipe.

Em relação ao fato de obterem adesão da equipe de trabalho às mudanças propostas após o curso, nos questionários predominou a concordância média para docentes e chefias e média e alta para os egressos, sendo que para este grupo foi identificado por $23 \%$ deles que não há adesão. Este achado nos levou a aprofundar a análise relativa a essa questão nos grupos focais (Tabela 5).

\section{Tabela 5 - Distribuição percentual das opiniões dos participantes quanto à adesão da equipe de trabalho para as mudanças propostas, no curso de técnico em gestão.} Natal/RN, 2008

\begin{tabular}{cccc}
\hline Concordância & Egressos (\%) & Docentes (\%) & Chefias (\%) \\
\hline Nenhuma & 23 & - & - \\
Pouca & 5 & - & 20 \\
Média & 36 & 50 & 60 \\
Alta & 36 & - & - \\
Muito alta & - & - & - \\
Faltam & - & 50 & 20 \\
Elementos & & & \\
\hline Total & $\mathbf{1 0 0}$ & $\mathbf{1 0 0}$ & $\mathbf{1 0 0}$ \\
\hline
\end{tabular}

No grupo focal dos egressos, quando instigados a refletirem sobre o porquê da falta de apoio dos colegas, alguns pontos importantes foram comentados: 1) há dificuldade dos colegas em aceitarem os processos educativos de outros; 2) há um acréscimo de trabalho para aqueles que permanecem nos serviços, considerando o já insuficiente número de servidores; 3) há uma falta de compreensão quanto à necessidade de mudanças provocadas pelos novos conhecimentos trazidos pelos colegas alunos-trabalhadores; e 4) há uma atitude de reação negativa a mudanças, pois a situação atual é cômoda e satisfatória.

No grupo focal dos chefes imediatos as dificuldades no estabelecimento de uma boa relação teoria e prática foram creditadas a aspectos mais amplos, entre eles a pouca estrutura do serviço e aos aspectos pessoais como, por exemplo, as atitudes desfavoráveis para mudanças.

Já entre os egressos, os relatos apontam para uma frustração pessoal, provocada por uma autoresponsabilização por não conseguirem implementar mudanças nos processos de trabalho a partir dos conhecimentos adquiridos. Isto é, a partir da orientação da Escola que teriam responsabilidades de transformar suas práticas, em isso não se estabelecendo na prática, há um sentimento de desânimo, descrédito, apaixonadamente descrito pelos egressos.

Em relação a estas questões, Cecílio, Mendes (2004), afirmam que os trabalhadores, com seus interesses e com sua prática, vão construindo múltiplos campos de relações de força que "deformam" as diretrizes da gestão, de forma que os dispositivos pensados para a implementação de tais diretrizes são reinterpretados e reapropriados com novos sentidos, quase sempre em consonância com antigas práticas e valores já bem estabelecidos. Assim, regras formais e informais são estabelecidas e quase sempre tem a potencialidade para influenciar e modificar o projeto de gestão da atual administração. Estas questões podem 
explicar a falta de adesão dos colegas às propostas de mudanças sugeridas pelos egressos, mesmo quando têm apoio da gestão.

Neste aspecto, a área administrativa da unidade hospitalar é reconhecida como a mais estruturada, com normas e rotinas estabelecidas, com linhas de mando bem verticalizadas e legitimadas, sendo seu corpo profissional o mais silencioso dentro do hospital, embora detenha recursos estratégicos para a gestão do cotidiano (CECÍLIO, MENDES, 2004).

Esta constatação nos remete para um questionamento sobre a função social do CEFOPE: que Escola queremos e podemos ter? Uma escola que possa responsabilizar-se ou contribuir para mudanças nos serviços de saúde ou uma Escola que tenha como função oferecer aos alunostrabalhadores os conhecimentos para que eles venham a traçar seus caminhos futuros? Quais os limites entre "responsabilizar-se" e "contribuir"?

Esta discussão está posta, principalmente considerando que o CEFOPE/RN faz parte da Rede de Escolas Técnicas do SUS conformada nos seus primórdios a partir da implantação dos Centros de Formação de Pessoal para os Serviços de Saúde que surgiram com a necessidade de oferecer qualificação para os trabalhadores já inseridos nos serviços de saúde, com o objetivo claro e definido: transformar qualitativamente o seu processo de trabalho (PEREIRA, RAMOS, 2006).

Assim, em que medida os limites desta responsabilização estão sendo definidos e tratados pela direção, pela equipe técnico-pedagógica e pelos docentes? Como eles estão sendo interpretados e incorporados pelos egressos? Alguns docentes relataram que o conhecimento permite expectativa de melhor qualidade do trabalho, em um sentido linear. Pelos depoimentos obtidos junto aos docentes parece não estar claro que o domínio do conteúdo técnico do trabalho por parte dos trabalhadores é apenas um dos componentes da qualidade do serviço. Outros fatores influenciam fortemente nesta direção, tais como o subfinanciamento, as políticas precárias de gestão do trabalho, a gestão em si, os descompassos entre as necessidades de atenção à saúde da população e os modelos de organização dos serviços.

Nesta questão, parece que os chefes têm maior clareza das limitações e responsabilidades da formação no que se refere a uma melhor qualidade do processo de trabalho em saúde. Para eles parece estar claro que a formação profissional na área de gestão, atualmente oferecida pela Escola é uma oportunidade de aprendizagem, avaliando ainda que responde a uma dívida antiga e que merece continuidade e ampliação. Entretanto, não há relação linear entre a formação e a melhoria da qualidade dos serviços em função de outros fatores intervenientes nos processos de mudança que transcendem a questão do conhecimento técnico e, inclusive, da concepção de atenção integral à saúde.

Quando estimulados a opinarem sobre a existência de apoio dos níveis mais elevados de gestão às mudanças propostas, $63 \%$ dos egressos e $50 \%$ dos docentes apresentaram pouca e média concordância; já a maioria das chefias mostrou concordância alta (60\%) (Tabela 6). 
Tabela 6 - Distribuição percentual das opiniões dos participantes quanto à existência de apoio dos níveis mais elevados de gestão às mudanças propostas, no curso de técnico em gestão. Natal/RN, 2008

\begin{tabular}{cccc}
\hline Concordância & Egressos (\%) & Docentes (\%) & Chefias (\%) \\
\hline Nenhuma & 05 & - & - \\
Pouca & 27 & 33 & - \\
Média & 35 & 17 & 40 \\
Alta & 23 & - & 60 \\
Muito alta & 05 & - & - \\
Faltam Elementos & 05 & 50 & - \\
\hline Total & $\mathbf{1 0 0}$ & $\mathbf{1 0 0}$ & $\mathbf{1 0 0}$ \\
\hline
\end{tabular}

Quanto à existência de infra-estrutura adequada à implementação das mudanças, $43 \%$ dos egressos exprimiram nenhuma concordância, os docentes $(50 \%)$ atribuíram menor concordância, a opinião dos chefes ficou dividida entre média e alta concordância (Tabela 7).

Tabela 7 - Distribuição percentual das opiniões dos participantes quanto à existência de infra-estrutura adequada para implementação das mudanças, no curso de técnico em gestão. Natal/RN, 2008

\begin{tabular}{cccc}
\hline Concordância & Egressos (\%) & Docentes (\%) & Chefias (\%) \\
\hline Nenhuma & 43 & - & - \\
Pouca & 29 & 50 & - \\
Média & 14 & - & 40 \\
Alta & 14 & - & 40 \\
Muito alta & - & - & - \\
Faltam Elementos & - & 50 & 20 \\
\hline Total & $\mathbf{1 0 0}$ & $\mathbf{1 0 0}$ & $\mathbf{1 0 0}$ \\
\hline
\end{tabular}

Nos grupos focais ainda foram abordados aspectos que podem demonstrar a amplitude destes problemas, como os relacionados à falta de qualificação dos gestores. Grande parte deles é profissional da área da saúde, sem conhecimentos específicos em administração da saúde pública e com pouco acesso, como os egressos, aos processos de formação nessa área.

Os participantes também emitiram graus de concordância alta e muito alta nos três grupos, quanto à necessidade das aulas privilegiarem metodologias que contribuam para a reflexão sobre situações vivenciadas no trabalho (Tabela 8).

Tabela 8 - Distribuição percentual das opiniões dos participantes quanto à necessidade das aulas privilegiarem metodologias que contribuam para a reflexão sobre situações vivenciadas no trabalho, no curso de técnico em gestão. Natal/RN, 2008

\begin{tabular}{cccc}
\hline Concordância & Egressos (\%) & Docentes (\%) & Chefias (\%) \\
\hline Nenhuma & - & - & - \\
Pouca & - & - & - \\
Média & 15 & - & 20 \\
Alta & 30 & - & 60 \\
Muito alta & 50 & 100 & 20 \\
Faltam & 5 & - & - \\
Elementos & & & $\mathbf{1 0 0}$ \\
\hline Total & $\mathbf{1 0 0}$ & $\mathbf{1 0 0}$ &
\end{tabular}


No grupo focal dos docentes, um dos relatos sobre esta questão explicitou que o processo de formação deixa o aluno-trabalhador menos repetitivo, tornando-o cidadão crítico e com maior possibilidade de sugerir soluções de problemas. Esta afirmativa corrobora com a identificação de uma concepção de trabalho que permita aos alunos-trabalhadores atitudes críticas, reflexivas e de maior autonomia, portanto, de maior domínio sobre o conteúdo do próprio trabalho.

Pela análise dos questionários e dos grupos focais percebe-se que o caminho da articulação entre a teoria e a prática ainda merece ser mais estudado e incorporado pelos sujeitos da educação profissional em saúde, especialmente quando se tem como horizonte da formação profissional sua repercussão nas mudanças dos processos de trabalho dessa área na perspectiva da atenção integral à saúde da população, caso da Rede de Escolas Técnicas do SUS, na qual está incluído o CEFOPE/RN.

\section{O CURRÍCULO E SEUS COMPONENTES}

Ao serem abordados em relação à importância concedida aos conteúdos técnicos específicos, aos conteúdos gerais da saúde e aos conteúdos relacionados à compreensão da sociedade, do Estado e do papel dos serviços de atenção à saúde da população como direito de todos (a partir daqui referenciados como sociais), os egressos deram maior importância aos temas gerais da saúde, seguido pelos específicos e sociais (Tabelas 9, 10, 11).

Tabela 9 - Distribuição percentual das opiniões dos participantes quanto à importância concedida aos conteúdos gerais da saúde, no curso de técnico em gestão. Natal/RN, 2008

\begin{tabular}{cccc}
\hline Concordância & Egressos $(\boldsymbol{\%})$ & Docentes $(\boldsymbol{\%})$ & Chefias $(\boldsymbol{\%})$ \\
\hline Nenhuma & 0 & 0 & 0 \\
Pouca & 0 & 0 & 0 \\
Média & 10 & 0 & 0 \\
Alta & 45 & 50 & 60 \\
Muito alta & 45 & 33 & 20 \\
Faltam & 0 & 17 & 20 \\
Elementos & & & \\
\hline Total & $\mathbf{1 0 0}$ & $\mathbf{1 0 0}$ & $\mathbf{1 0 0}$ \\
\hline
\end{tabular}

Tabela 10 - Distribuição percentual das opiniões dos participantes quanto à importância concedida aos conteúdos técnicos específicos, no curso de técnico em gestão. Natal/RN, 2008

\begin{tabular}{cccc}
\hline Concordância & Egressos $(\boldsymbol{\%})$ & Docentes (\%) & Chefias (\%) \\
\hline Nenhuma & 0 & 0 & 0 \\
Pouca & 0 & 0 & 0 \\
Média & 14 & 0 & 0 \\
Alta & 33 & 16 & 40 \\
Muito alta & 53 & 68 & 0 \\
Faltam & 0 & 16 & 60 \\
Elementos & & & \\
\hline Total & $\mathbf{1 0 0}$ & $\mathbf{1 0 0}$ & $\mathbf{1 0 0}$ \\
\hline
\end{tabular}


Tabela 11 - Distribuição percentual das opiniões dos participantes quanto à importância concedida aos conteúdos sociais, no curso de técnico em gestão. Natal/RN, 2008

\begin{tabular}{cccc}
\hline Concordância & Egressos (\%) & Docentes (\%) & Chefias (\%) \\
\hline Nenhuma & 0 & 0 & 0 \\
Pouca & 05 & 0 & 0 \\
Média & 33 & 0 & 0 \\
Alta & 24 & 33 & 20 \\
Muito alta & 38 & 50 & 40 \\
Faltam & 0 & 17 & 40 \\
Elementos & & & \\
\hline Total & $\mathbf{1 0 0}$ & $\mathbf{1 0 0}$ & $\mathbf{1 0 0}$ \\
\hline
\end{tabular}

No entanto, no aprofundamento do grupo focal, no diálogo entre os egressos concluiu-se que os temas são igualmente importantes e que se completam. Advertiram, ainda, que a discordância dessa resposta com as dadas no questionário deveu-se à dificuldade que eles encontraram em respondê-lo.

No questionário, os docentes emitiram concordâncias iguais para os três grupos de conteúdos. No grupo focal houve diferentes opiniões entre eles, um docente reafirmou a igualdade de importância dos três temas para o curso de gestão, enquanto outro avalia que existe uma concepção hegemônica de que ações administrativas não requerem conhecimentos científicos e que há uma postura diferenciada nos serviços entre os trabalhadores que se envolvem em ações administrativas e em ações técnicas, reforçando assim a importância dos temas específicos.

Pela tabela verifica-se que os chefes deram maior importância aos temas gerais. Posteriormente, no grupo focal, revelaram que a importância dada aos temas sociais ocorreu devido ao fato de que a missão do hospital está voltada para a assistência à população, à necessidade de se trabalhar as relações humanas no trabalho, a educação permanente e o cuidado do trabalhador. Indicam que os temas gerais da saúde são próximos ao seu dia-a-dia, mas que precisam de uma melhor apropriação por parte dos trabalhadores e os temas específicos ficaram em menor grau de importância porque há um entendimento de que eles já conhecem todo o conteúdo do seu trabalho.

Estes dados nos remetem à discussão apresentada em documento produzido pelo Ministério da Educação onde é defendida uma proposta curricular que contemple os conhecimentos específicos de uma área profissional e uma formação geral, apontando ainda que para que isto seja possível, é necessário estudar os problemas de uma área profissional em múltiplas dimensões, tais como econômica, social, política, cultural e técnica (BRASIL, 2009).

\section{A RELAÇÃO ESTABELECIDA ENTRE A ESCOLA E OS SERVIÇOS DE SAÚDE}

O planejamento e desenvolvimento das aulas demonstram que o CEFOPE/RN conhece a realidade dos hospitais em que os egressos trabalham. Os docentes na sua totalidade concordaram com essa afirmação; entre os egressos, $75 \%$ optaram por média e pouca concordância, enquanto $10 \%$ deles discordaram; e as chefias, na sua maioria, não emitiram opiniões sobre a questão (Tabela 12). 
Tabela 12 - Distribuição percentual das opiniões dos participantes quanto à fato do planejamento das aulas demonstrarem que o CEFOPE conhece a realidade do hospital em que os alunos trabalham, no curso de técnico em gestão. Natal/RN, 2008

\begin{tabular}{cccc}
\hline Concordância & $\begin{array}{c}\text { Egressos } \\
(\%)\end{array}$ & Docentes (\%) & Chefias (\%) \\
\hline Nenhuma & 10 & - & - \\
Pouca & 25 & - & - \\
Média & 50 & - & 20 \\
Alta & 10 & 50 & 20 \\
Muito alta & 05 & 33 & - \\
Faltam & - & 17 & 60 \\
Elementos & & & $\mathbf{1 0 0}$ \\
\hline Total & $\mathbf{1 0 0}$ & $\mathbf{1 0 0}$ &
\end{tabular}

Em razão das discrepâncias decorrentes das respostas ao questionário, o tema foi levado aos grupos focais. Nessa perspectiva, o aprofundamento da questão foi esclarecedor, pois houve convergência entre os três grupos em torno da idéia de que a articulação entre o CEFOPE/RN e as unidades hospitalares é incipiente. Além disso, a opinião dos grupos converge no sentido de que a escola necessita conhecer melhor a realidade dos serviços, pois a falta desse conhecimento gerou alguns problemas durante o curso.

Ao serem abordados se o entendimento prévio entre a direção dos hospitais, o CEFOPE/RN e os egressos contribuiu para o bom desenvolvimento das atividades acadêmicas, todos os grupos tiveram alto percentual de concordância, sendo que $10 \%$ dos egressos discordaram da afirmação.

Os chefes (100\%), durante o grupo focal, recomendaram ao CEFOPE/RN uma maior articulação com as unidades hospitalares, sugeriram que essas deveriam ser convidadas regularmente para discutirem com a escola a programação e o planejamento dos cursos, levantando, inclusive, as demandas para proporem os cursos de acordo com a realidade vivida na unidade. Isto, segundo os chefes, contribuiria muito nesta relação ensino e serviço.

Uma questão colocada pelos atores deste estudo se refere ao papel do CEFOPE/RN. Os docentes e os chefes, majoritariamente, acreditam que o Centro deve ir além da oferta de cursos, que deve interagir mais profundamente com as unidades hospitalares e acompanhar o desenvolvimento dos alunos-trabalhadores na pós-formação. Por outro lado, a posição majoritária dos egressos é no sentido de que a função da escola é ministrar os cursos.

Para Pereira e Ramos (2006), segundo entrevista com a Enfermeira Izabel Santos, entre as causas da desarticulação escola-serviços, está o modelo de escola que trabalha o conhecimento sem um compromisso real com a prática profissional. Nessa concepção de escola, o que existe é a valorização do conhecimento pelo conhecimento.

Neste sentido, se o CEFOPE/RN deseja realmente atender ao requisito de uma escola comprometida com uma mudança de prática nos serviços é fundamental que esta relação se estabeleça de forma intrínseca e como condição de seu exercício formador.

Pereira e Ramos (2006) alertam que especificamente em relação à educação profissional em saúde é importante compreender que a lógica da integração ensino-serviço apresenta limites enquanto estiver circunscrita aos aspectos metodológicos e não avançar para a construção de referenciais políticos e epistemológicos da educação profissional em saúde. 
A concepção da atenção em saúde pode ser compreendida como a ação humana destinada ao cuidado do/com o outro, assim o trabalhador não é uma mercadoria, o trabalhador não é um recurso e a educação não se reduz ao método e finalizam a idéia afirmando que a formação do trabalhador em saúde, muito além de ser orientada pelo e para os serviços de saúde, estando a eles integrada, deve ser orientada pela e para a emancipação humana, devendo se integrar à totalidade contraditória da realidade social (PEREIRA, RAMOS, 2006).

A necessária integração entre o ensino e o serviço não está presente apenas na educação profissional. Ela é uma defesa feita por estudiosos da educação como um todo, que a entendem como fonte e parâmetro para a rearticulação da teoria-prática, apontando ainda para que os currículos sejam construídos visando que os profissionais tenham habilidades e competências para atuar de forma consciente e reflexiva frente às reais necessidades e prioridades de saúde da população (PINHEIRO, LOPES, OHIRA, NICOLETTO, 2003).

Tal defesa se articula com os conceitos da integralidade, seja na sua responsabilidade de oferecer uma atenção integral aos problemas da população, seja na sua vertente de tomar a integralidade como uma oportunidade de oferecer ao aluno uma formação ampla, na qual a educação geral se torne inseparável da educação profissional, superando o ensino meramente instrumental da preparação para o trabalho no seu aspecto operacional (HANSEN, 2007). Ou seja, a integralidade pode se transformar em uma práxis na educação profissional a partir da concepção de politecnia.

\section{CONCLUSÕES}

A partir dos achados desta pesquisa foi possível concluir que o CEFOPE/RN vem construindo caminhos em direção à organização da prática pedagógica utilizando os serviços de saúde como eixo de uma formação voltada para a melhoria desses serviços na perspectiva do atendimento integral. Algumas lacunas persistem e indicam a necessidade de uma maior reflexão para correção de rumos e novos redirecionamentos.

Especificamente em relação à aplicação dos conhecimentos teórico-práticos no seu trabalho ratifica-se que existem algumas incompreensões, interpretações inadequadas e conflitos em relação à articulação teoria e prática, geradas por processos históricos de formação intelectual e pelas dificuldades atuais de reflexão sobre o objeto de trabalho dos atores das Escolas Técnicas do SUS. Neste sentido, a comunidade escolar do CEFOPE/RN necessita ampliar esse processo de reflexão, proporcionando aos egressos e chefes imediatos uma real compreensão da importância, especialmente das responsabilidades e limitações da contribuição da formação profissional na qualidade dos serviços.

Algo muito positivo e coerente emergiu dos resultados da pesquisa, qual seja, a convergência entre os três grupos investigados acerca da contribuição do curso no sentido de proporcionar/ampliar o domínio dos alunos-trabalhadores sobre o conteúdo do próprio trabalho. Termos como: domínio técnico e autonomia sobre o trabalho, compreensão do significado do trabalho entre outros foram utilizados de forma recorrente pelos sujeitos para se referirem às contribuições do curso no que diz respeito à relação entre os egressos e o próprio trabalho.

Além disto, a análise também permite concluir que o curso contribui para ampliar/proporcionar aos alunos-trabalhadores a compreensão das atividades da área da gestão desenvolvidas nos outros setores das unidades hospitalares, assim como a relevância 
do trabalho desse conjunto - área de gestão - no que tange à atenção integral à saúde da população, mesmo que em suas ações específicas do cotidiano eles não tenham contato direto com os usuários do SUS. Assim sendo, o curso, apesar das inúmeras dificuldades apontadas e que demandam ações voltadas à sua melhoria, promove a qualificação técnica e social dos alunos-trabalhadores, possibilitando-lhes um maior domínio sobre o conteúdo do próprio trabalho do ponto de vista técnico e do sentido que tem para a população usuária do SUS.

Destaca-se ainda, face aos resultados, a necessidade do CEFOPE/RN promover maior articulação com as unidades hospitalares com vistas a favorecer a integração entre ensino e serviço.

Finalizando, realizar esta pesquisa foi um grande desafio para o CEFOPE/RN, entendendo ser este um caminho muito importante para o fortalecimento da educação profissional em saúde.

\section{REFERÊNCIAS}

1. BRASIL. Ministério da Educação. Educação profissional técnica de nível médio integrada ao ensino médio: Documento base. Disponível em: <http://portal.mec.gov.br $>$. Acesso em: 02 jun.2009

2. CECÍLIO, L. C. O.; MENDES, T. C.. Propostas alternativas de gestão hospitalar e o protagonismo dos trabalhadores: por que as coisas nem sempre acontecem como os dirigentes desejam. Saúde e Sociedade, São Paulo, v. 13, n. 2, p. 39-55, 2004. Trimestral. Publicação referente ao período de maio a agosto. ISSN 0104-1290.

3. GATTI, B. A. Grupo focal na pesquisa em ciências sociais e humanas. Brasília: Líber Livro, 2005.

4. HANSEN, L.M.M. É possível inserir a integralidade na formação técnica em saúde. In: LOPES, M.G.M. (Org). Saúde bucal coletiva: implementando idéias, concebendo integralidade. Rio de Janeiro: Rúbio, 2007.

5. MINAYO, M.C.S, SANCHES, O. Quantitativo-qualititativo: oposição ou complementaridade?. Cad. Saúde Pública. Rio de Janeiro, 9 (3): 239-262, jul/set, 1993.

6. MINAYO, M. C. S. (org). Pesquisa social: teoria, método e criatividade. Petrópolis: Vozes, 1994.

7. . O desafio do conhecimento: pesquisa qualitativa em saúde. Rio de Janeiro: Hucitec-ABRASCO, 1996.

8. MINAYO M. C. S. et al. Métodos, técnicas e relações em triangulação. In: MINAYO M. C. S.; ASSIS, S. G.; SOUZA, E. R. (Orgs.). Avaliação por triangulação de métodos: abordagem de programas sociais. Rio de Janeiro: FIOCRUZ, 2005. p. 71-103.

9. PEREIRA, I.B, RAMOS, M.R. Educação Profissional em Saúde. Rio de Janeiro: Editora Fiocruz, 2006. 120 p.

10. PINHEIRO, E.F.C., LOPES, M.L.S.,OHIRA, R.H.F., NICOLETTO S.C.S. Profissional de saúde: a inter-relação entre formação e prática. Revista Formação: estudos, reflexões e experiências em educação profissional na saúde. Brasília, v. 3, n. 8, maio 2003. Publicação do Ministério da Saúde. 
11. RIO GRANDE DO NORTE (Estado). Secretaria de Saúde. Centro de Formação de Pessoal para os Serviços de Saúde Dr. Manoel da Costa Souza. Projeto Político Pedagógico. Natal: [s.n.], 2004.

12. SAVIANI, D. O choque teórico da Politécnia. Revista Trabalho, Educação e Saúde. Brasília, v. 1, n. 1, mar. 2003. Publicação do Ministério da Saúde.

13. SÓRIO, R.E.R. Educação profissional em saúde no Brasil: a proposta das Escolas Técnicas de Saúde do Sistema Único de Saúde. Revista Formação: formação técnica em saúde no contexto do SUS. Brasília, v. 2, n. 5, maio 2002. Publicação do Ministério da Saúde.

\section{AGRADECIMENTOS}

Ao Ministério da Saúde, através da Secretaria de Gestão do Trabalho e da Educação na Saúde/Departamento de Gestão da Educação em Saúde e à Secretaria de Estado da Saúde Pública do RN através do Centro de Formação de Pessoal para os Serviços de Saúde Dr. Manoel da Costa Souza pelo apoio e financiamento da pesquisa.

Ao Professor Gaudêncio Frigotto, pela orientação inicial ao projeto da pesquisa. Aos colegas integrantes da equipe inicial da pesquisa e à Direção e Equipe técnico-pedagógica e administrativa do CEFOPE/RN, pelo apoio e incentivo dispensado na execução da pesquisa. 